\title{
Doses de potássio e lâminas de irrigação na qualidade de mudas de eucalipto
}

\author{
Antonio Henrique Cordeiro RAMALHO ${ }^{1 *}$, Fernanda Dalfior MAFFIOLETTI ${ }^{1}$, Paulo André TRAZZI², \\ Eduardo Cordeiro RAMALHO ${ }^{3}$, Nilton Cesar FIEDLER ${ }^{1}$
}

\author{
${ }^{1}$ Departamento de Ciências Florestais e da Madeira, Universidade Federal do Espírito Santo, Alegre, ES, Brasil. \\ (Orcid: *; 0000-0002-2198-8412; 0000-0002-3895-661X) \\ ${ }^{2}$ Universidade do Estado de Minas Gerais, Ituiutaba, MG, Brasil. (Orcid: 0000-0003-4255-3466) \\ ${ }^{3}$ Universidade Estácio de Sá, Colatina, ES, Brasil. (Orcid: 0000-0002-8151-0170) \\ *E-mail: henriqueramalho14@gmail.com (Orcid: 0000-0002-0037-5422)
}

Recebido em 11/04/2020; Aceito em 22/09/2020; Publicado em 05/10/2020.

\begin{abstract}
RESUMO: A produtividade florestal depende das potencialidades genéticas das matrizes, do ambiente proposto pelos substratos, frequência de irrigação, disponibilidade de luz, nutrição e das condições fitossanitárias. Assim, objetivou-se com o presente estudo analisar os efeitos da aplicação de potássio e de irrigação na qualidade de mudas de Eucalyptus urophylla. Para tal adotou-se o delineamento experimental em parcelas subdivididas definindo as 2 lâminas de irrigação $(10 \mathrm{~mm}$ e $15 \mathrm{~mm})$ como parcelas e os 5 níveis de potássio $\left(0 ; 1,2 ; 2,4 ; 4,8 ;\right.$ e $\left.9,6 \mathrm{~g} \mathrm{~L}^{-1}\right)$ como subparcelas, em 5 repetições compostas por 9 plantas. A comparação entre os métodos foi feita através teste de Tukey com 5\% de probabilidade. Aos 120 dias, foram avaliadas: altura da parte aérea, diâmetro do colo, massa seca da parte aérea e da raiz. O tratamento testemunha apresentou as melhores médias em todos os parâmetros, sendo considerado o mais eficiente. A lâmina de irrigação de 15 $\mathrm{mm}$ foi considerada a mais eficiente. Portanto, conclui-se que qualquer que seja o incremento de potássio na produção de mudas, o mesmo deve se relacionar harmonicamente com a quantidade pré-existente no substrato base e com as exigências da cultura, de maneira que haja equilíbrio entre todas as partes.
\end{abstract}

Palavras-chave: manejo hídrico; rustificação; substrato; casa de sombra.

\section{Irrigation and potassium levels in the quality of eucalyptus}

\begin{abstract}
Forest productivity depends on the genetic potential of the matrices, the environment proposed by the substrates, frequency of irrigation, availability of light, nutrition and phytosanitary conditions. Thus, the aim of this study was to analyze the effects of potassium and irrigation on the quality of Eucalyptus urophylla seedlings. For this purpose, the experimental design was adopted in subdivided plots, defining the 2 layers of irrigation (10 $\mathrm{mm}$ and $15 \mathrm{~mm})$ as plots and the 5 levels of potassium $\left(0 ; 1.2 ; 2.4 ; 4.8\right.$; and $\left.9.6 \mathrm{~g} \mathrm{~L}^{-1}\right)$ as subplots, in 5 repetitions composed of 8 plants. The comparison between the methods was made using the Tukey test with a 5\% probability. At 120 days, the following were evaluated: height of the aerial part, diameter of the neck, dry mass of the aerial part and the root. The control treatment showed the best averages in all parameters, being considered the most efficient. The $15 \mathrm{~mm}$ irrigation blade was considered the most efficient. Therefore, it is concluded that whatever the potassium increase in the production of seedlings, it must be harmoniously related to the pre-existing quantity in the base substrate and to the requirements of the culture, so that there is balance between all parts.
\end{abstract}

Keywords: water management; rustification; substrate; shadow house.

\section{INTRODUÇÃO}

O êxito na formação de povoamentos florestais produtivos depende tanto das potencialidades genéticas das sementes quanto das condições proporcionadas pelos substratos, frequência de irrigação, disponibilidade de luz, nutrição mineral e das condições fitossanitárias (BUSATO et al., 2016; MARTINS et al., 2018; RESENDE et al., 2018). Com isso, a produção de mudas de qualidade em viveiros, tornou-se algo imprescindível para atender à crescente demanda do setor florestal (BATTIE-LACLAU et al., 2016; SOUZA; PERES, 2016).

A frequência de irrigação pode culminar em duas situações problema, uma ocasionada pelo excesso e outra pelo déficit hídrico nas mudas, onde ambas são consideradas danosas à qualidade dos indivíduos produzidos (MARGUERIT et al., 2014). O déficit hídrico pode influenciar em diversos processos metabólicos das mudas florestais, como o fechamento estomático, diminuição da taxa fotossintética e de transpiração, causando o declínio de produção e de crescimento das mesmas (HERNANDEZSANTANA et al., 2017; QUEIROZ et al., 2017; FERNÁNDEZ et al., 2018). Sendo assim, torna-se clara a necessidade de padronização e redefinição da quantidade hídrica a ser disponibilizada na fase de viveiro para garantir a maior eficiência na utilização de água de maneira a não prejudicar a qualidade física e fisiológica das mudas (FERNÁNDEZ et al., 2018; GIRARDI et al., 2018; ZENG et al., 2018).

Aliada aos problemas causados pela disponibilidade de recursos hídricos, destaca-se a nutrição silvicultural, haja visto que a insuficiência mineral influencia diretamente no desenvolvimento qualitativo das mudas florestais, pois 
diminui a adaptação e sobrevivência das mesmas após seu plantio em campo (BATTIE-LACLAU et al., 2016; FERNANDES et al., 2018; FERNÁNDEZ et al., 2018). De acordo com D’Avila et al. (2011), uma alternativa viável, é a utilização de cloreto de potássio $(\mathrm{KCl})$, acondicionado ao substrato, de maneira a potencializar os efeitos da rustificação das mudas e assim diminuir a lâmina de irrigação em todo o processo de produção. A utilização de tal tipo de fertilização mineral destaca-se por proporcionar maior resistência durante os períodos secos e de geadas e por aumentar o potencial de retenção hídrica nos indivíduos nutridos, suficientemente, com o potássio (K) (GONÇALVES et al., 2015; BATTIE-LACLAU et al., 2016).

Embora não tenha função estrutural na planta, o potássio é um importante macronutriente para atuar na ativação de cerca de 50 enzimas (TAVARES et al., 2013; MARQUES et al., 2018). Em situações de baixo potencial hídrico, o K destaca-se por ser o principal íon presente nos vacúolos celulares relacionados ao controle osmótico e consequente transpiração, sendo de extrema importância na manutenção da turgidez interna das células (D'AVILA et al., 2011; BATTIE-LACLAU et al., 2016).

O estudo da influência e dos efeitos da utilização do potássio na produção de mudas de Eucalyptus spp., assim como na eficiência da utilização da água pelas mesmas é fundamental, pois existe ainda uma carência acerca dos dados referentes à utilização do macronutriente nas mudas de eucalipto e por que toda informação científica com potencial de auxiliar na redução do uso de água na produção de mudas florestais, configura-se em uma importante ferramenta sustentável à atividade. Sendo assim, com o presente estudo objetivou-se a avaliação dos efeitos da fertilização mineral, com base na introdução de $\mathrm{KCl}$, na otimização do uso dos recursos hídricos na produção de mudas de Eucalyptus urophylla $S$., de maneira a manter ou elevar a qualidade das mudas.

As hipóteses que norteiam o presente estudo são: 1) maiores doses de potássio garantirão melhores resultados acerca da economia hídrica; e 2) ainda que com menores lâminas de irrigação, as mudas apresentarão boa produtividade.

\section{MATERIAL E MÉTODOS}

\section{1. Área de estudo}

O experimento foi conduzido no viveiro florestal do Instituto Federal do Norte de Minas Gerais (IFNMG) Campus Salinas, MG, Brasil (16 $\left.{ }^{\circ}\right)^{\prime} \mathrm{S} ; 42^{\circ} 18^{\prime} \mathrm{O}$; $471 \mathrm{~m}$ de altitude). A área situa-se na região fisiográfica do chapadão do Itacambira - Vale do Jequitinhonha. De acordo com o sistema de classificação de Köppen, o clima predominante na região é do tipo Aw (ALVARES et al., 2014), caracterizado pelo inverno seco e verão chuvoso, com temperatura média anual de $24{ }^{\circ} \mathrm{C}$ e precipitação anual média de $827,7 \mathrm{~mm}$ (PEGO et al., 2015).

\subsection{Confecção e condução do experimento}

O presente estudo seguiu uma ordem cronológica de execução de acordo com o fluxograma apresentado na Figura 1. As mudas foram confeccionadas em bandejas de 187 células; e tubetes de polipropileno com seis estrias internas, volume de $55 \mathrm{~cm}^{3}$ e dimensões de 125,34 e $29 \mathrm{~mm}$ de altura, diâmetros externo e interno, respectivamente. Os recipientes foram preenchidos com substrato comercial composto por casca de pinus, cinza, fosfato natural, vermiculita, serragem, bioestabilizados e adubo químico NPK juntamente com as doses de $\mathrm{KCl}$ conforme proposto por D’Ávila et al. (2011), sendo representadas pelos seguintes tratamentos: T1 (Testemunha), sem adição de KCl; T2: $2 \mathrm{~g} \mathrm{~L}^{-1}$ de KCl; T3: 4 $\mathrm{g} \mathrm{L}^{-1}$ de KCl; T4: $8 \mathrm{~g} \mathrm{~L}^{-1}$ de $\mathrm{KCl}$; e T5: $16 \mathrm{~g} \mathrm{~L}^{-1}$ de $\mathrm{KCl}$. Vale ressaltar que o $\mathrm{KCl}$ apresenta, em sua composição, 60\% de potássio (LIMA et al., 2016).

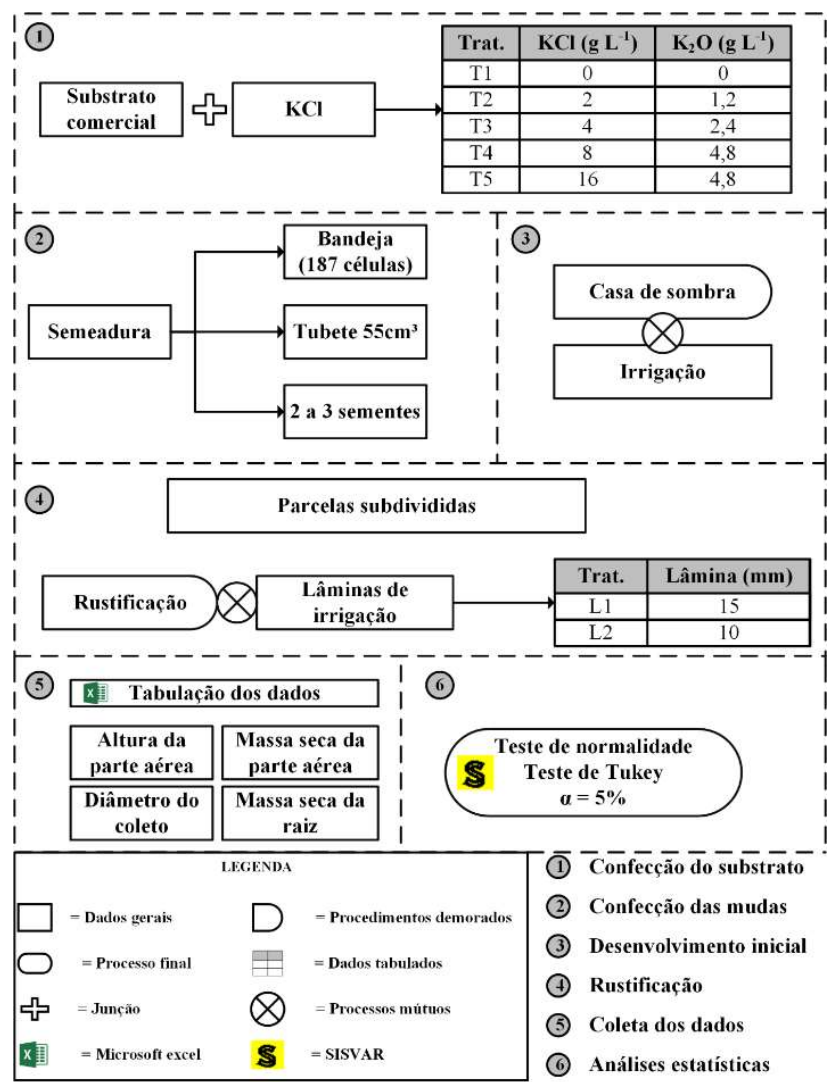

Figura 1. Fluxograma das etapas metodológicas.

Figure 1. Flowchart of methodological steps.

Em cada tubete adicionou-se entre duas a três sementes de Eucalyptus urophylla, de maneira a permitir a realização do raleio no intuito de eliminar as mudas excedentes em cada tubete, permanecendo apenas a mais central e vigorosa. Após a etapa de preparação do substrato e recipientes, as mudas permaneceram em casa de sombra, para desenvolvimento inicial, por 60 dias, submetidas à lâmina de irrigação de $8 \mathrm{~mm}$ $\mathrm{dia}^{-1}$.

Em sequência, iniciou-se a fase de rustificação, em que cada um dos tratamentos recebeu duas lâminas de irrigação: L1 $(15 \mathrm{~mm})$ e L2 $(10 \mathrm{~mm})$, as quais foram aplicadas duas vezes ao dia, sempre às $08 \mathrm{~h} 00$ e $16 \mathrm{~h} 00$, durante 60 dias, conforme sugerido por Alfenas et al. (2009), Rodrigues et al. (2011) e Silva et al. (2015). A irrigação das mudas foi realizada por meio de um sistema de micro aspersão automatizado.

\subsection{Variáveis avaliadas}

Para avaliar a qualidade das mudas produzidas foram avaliadas as seguintes variáveis: altura da parte aérea (HPA); e o diâmetro do coleto (DC). A atividade seguiu ordem cronológica: (1) retirada das mudas dos substratos e limpeza do sistema radicular; (2) separação da parte aérea (PA) e das raízes; (3) mensuração da PA (diâmetro do coleto e altura); (4) separação de amostras e pré secagem; (5) alocação em 
estufa; e (6) pesagem da massa seca da PA e do sistema radicular.

Utilizando paquímetro digital de $\pm 0,02 \mathrm{~mm}$ de precisão e régua graduada foi possível mensurar os parâmetros sugeridos para a parte aérea das mudas de espécies florestais. A altura da parte aérea foi mensurada por meio de régua graduada, seguindo o padrão de início no coleto e término no ponto mais alto do caule.

A parte aérea foi separada do sistema radicular com o auxílio de tesoura comum, onde foram efetuados cortes únicos na interseção entre as duas partes (coleto). Após a mensuração das mudas, essas foram colocadas à pleno sol para a secagem ao ar livre antes de serem alocadas em estufa. Com 4 dias de pré secagem, os pacotes foram postos na estufa, regulada para $75^{\circ} \mathrm{C}$, até que o material atingisse a massa constante. Após o período de estufa foi dado início à pesagem da massa seca da parte aérea (MSPA) e da massa seca da raiz (MSR), com uma balança de precisão eletrônica de $\pm 0,01 \mathrm{~g}$.

Foram utilizados cálculos de porcentagem (Eq. 1) para definir quais variáveis estudadas sofreram maiores influências dos tratamentos de doses de $\mathrm{K}$ e lâminas de irrigação.

$$
\mathrm{DP}=\left(\frac{\mathrm{MR}-\mathrm{PR}}{\mathrm{MR}}\right) \times 100
$$

em que: $\mathrm{DP}=$ discrepância percentual, $\% ; \mathrm{MR}=$ melhor resultado; e PR $=$ pior resultado.

\subsection{Procedimentos estatísticos}

Para avaliar o efeito do $\mathrm{K}$ no processo de rustificação das mudas de eucalipto foram organizadas parcelas com 8 repetições, adotando o arranjo experimental em parcelas subdivididas em 5 (níveis de adubação de base de potássio) x 2 (níveis de lâminas de irrigação). Cada repetição foi composta por 9 plantas, totalizando 720 plantas no experimento.

A análise estatística foi realizada utilizando-se o programa SISVAR 5.6 (FERREIRA, 2014). Após comprovação da distribuição normal dos dados e homogeneidade de variâncias, foi realizado um teste $\mathrm{F}(\mathrm{p}<0,05)$ para verificação $\mathrm{da}$ diferenciação entre os tratamentos para determinada característica, e quando significativo, foi feito o teste de Tukey $(p<0,05)$ para discriminação de diferenças estatísticas entre as médias dos tratamentos de cada fator.

\section{RESULTADOS}

$\mathrm{A}$ análise de variância das doses de $\mathrm{K}_{2} \mathrm{O}$ e das lâminas de irrigação acerca da HPA, DC, MSPA e MSR estão dispostos na Tabela 1

Os valores médios e seus respectivos desvios padrões da altura da parte aérea, diâmetro do coleto, massa seca da parte aérea e massa seca da raiz, de ambas as lâminas são expressos na Tabela 2.

Tabela 1. Resultados da ANOVA da altura da parte aérea (HPA), diâmetro do coleto (DC), massa seca da parte aérea (MSPA) e massa seca da raiz (MSR) em duas lâminas de irrigação e cinco doses de $\mathrm{K}_{2} \mathrm{O}$.

Table 1. ANOVA results of shoot height (HPA), shoot diameter (DC), shoot dry mass (MSPA) and root dry mass (MSR) in two irrigation and five $\mathrm{K}_{2} \mathrm{O}$ levels.

\begin{tabular}{cccc}
\hline \multirow{2}{*}{ Fonte de variação } & \multirow{2}{*}{ Soma dos quadrados } & Quadrado médio & Fc (significância) \\
\cline { 3 - 4 } & 132,638 & & HPA (cm) \\
\hline Irrigação (A) & 462,162 & 132,638 & $13,732^{*}$ \\
Dose (B) & 171,471 & 115,540 & $23,344^{*}$ \\
Irrigação x Dose & - & 42,867 & $8,661^{*}$ \\
\hline- & 0,888 & & $14,193^{*}$ \\
\hline Irrigação (A) & 0,819 & 0,888 & $2,626^{*}$ \\
Dose (B) & 0,166 & 0,204 & $0,535^{\text {ns }}$ \\
Irrigação x Dose & - & 0,041 & $6,781^{*}$ \\
\hline- & 9,494 & & $39,742^{*}$ \\
\hline Irrigação (A) & 247,433 & 9,494 & $1,585^{\text {ns }}$ \\
Dose (B) & 9,867 & 61,858 & $88,753^{*}$ \\
Irrigação x Dose & - & 2,466 & \\
\hline- & 10,527 & & $23,252^{*}$ \\
\hline Irrigação (A) & 23,099 & 10,527 & $3,203^{*}$ \\
Dose (B) & 3,182 & 5,774 & 0,795 \\
Irrigação x Dose
\end{tabular}

em que: $\mathrm{Fc}=\mathrm{f}$ calculado; ${ }^{\text {ns }} \mathrm{F}$ não significativo a 0,05 de probabilidade; $\mathrm{e}^{*} \mathrm{~F}$ significativo a 0,05 de probabilidade.

Tabela 2. Valores médios da altura da parte aérea (HPA), diâmetro do coleto (DC), massa seca da parte aérea (MSPA) e massa seca da raiz (MSR).

Table 2. Mean values of shoot height (HPA), root collar diameter (DC), aerial shoot dry mass (MSPA) and root dry mass (MSR).

\begin{tabular}{ccccc}
\hline Lâminas de irrigação & HPA $(\mathrm{cm})$ & DC $(\mathrm{cm})$ & MSPA $(\mathrm{g})$ & MSR $(\mathrm{g})$ \\
\hline L1 & $18,34 \pm 4,85$ & $1,99 \pm 0,37$ & $6,34 \pm 2,25$ & $2,97 \pm 0,85$ \\
L2 & $15,77 \pm 2,82$ & $1,78 \pm 0,28$ & $5,65 \pm 2,26$ & $2,25 \pm 0,67$ \\
\hline
\end{tabular}

em que: L= Lâmina de Irrigação; HPA=Altura da Parte Aérea; DC= Diâmetro do Coleto; MSPA= Massa Seca da Parte Aérea; MSR= Massa seca da Raiz.

\subsection{Altura da parte aérea}

Os resultados da ANOVA para a altura da parte aérea demonstraram a existência de interação significativa entre os fatores principais (doses e lâminas de irrigação) pelo teste de $\mathrm{F}$ à $5 \%$ de probabilidade de erro, o que acarretou na necessidade de proceder com os desdobramentos de tais 
fatores e consequentemente a comparação de médias pelo teste de Tukey a $5 \%$ de probabilidade que são apresentados na Tabela 3.

A partir dos resultados apresentados na tabela foi possível delimitar que as melhores doses para cada lâmina de irrigação foram: (a) em L1, a testemunha $(22,90 \mathrm{~cm})$ e a dose de 2,4 $\mathrm{g} \mathrm{L}^{-1}(21,84 \mathrm{~cm})$, seguido pelo tratamento com 1,2 $\mathrm{g} \mathrm{L}^{-1}$ $(17,26 \mathrm{~cm})$; (b) em L2, a única dose que apresentou resultado inferior foi a de T5 $(13,21 \mathrm{~cm})$, sendo que as demais não apresentaram diferenças estatísticas. As doses que apresentaram melhores resultados sob influência das lâminas foram: $15 \mathrm{~mm}$ nas doses testemunha $(22,90 \mathrm{~cm}), 1,2 \mathrm{~g} \mathrm{~L}^{-1}$ $(17,26 \mathrm{~cm})$ e $2,4 \mathrm{~g} \mathrm{~L}^{-1}(21,84 \mathrm{~cm})$; sem diferença estatística nas doses $4,8 \mathrm{~g} \mathrm{~L}^{-1}$ e $9,6 \mathrm{~g} \mathrm{~L}^{-1}$.

\subsection{Diâmetro do coleto}

A análise de variância do diâmetro do coleto não apresentou interação significativa entre os fatores principais (doses e lâminas de irrigação) pelo teste $\mathrm{F}$ à $5 \%$ de probabilidade de erro. Os respectivos resultados foram submetidos ao teste de Tukey com 5\% de probabilidade e apresentados na Figura 2.

Tabela 3. Altura da parte aérea $(\mathrm{cm})$ em função das lâminas de irrigação e das doses de $\mathrm{K}_{2} \mathrm{O}$.

Table 3. Height of the aerial part $(\mathrm{cm})$ as a function of the irrigation and $\mathrm{K}_{2} \mathrm{O}$ levels.

\begin{tabular}{cccccc}
\hline Lâminas de & \multicolumn{5}{c}{ Doses de Potássio } \\
\cline { 2 - 6 } Irrigação & $0 \mathrm{~g} \mathrm{~L}^{-1}$ & $1,2 \mathrm{~g} \mathrm{~L}^{-1}$ & $2,4 \mathrm{~g} \mathrm{~L}^{-1}$ & $4,8 \mathrm{~g} \mathrm{~L}^{-1}$ & $9,6 \mathrm{~g} \mathrm{~L}^{-1}$ \\
\hline L1 & $22,90 \mathrm{aA}$ & $17,26 \mathrm{bA}$ & $21,84 \mathrm{aA}$ & $16,75 \mathrm{bA}$ & $12,95 \mathrm{cA}$ \\
$\mathrm{L} 2$ & $18,08 \mathrm{aB}$ & $14,86 \mathrm{abB}$ & $16,11 \mathrm{abB}$ & $16,55 \mathrm{abA}$ & $13,21 \mathrm{bA}$ \\
\hline
\end{tabular}

em que: Médias seguidas pela mesma letra maiúscula nas colunas e minúscula nas linhas não diferem pelo teste de Tukey a 5\% de probabilidade ( $\mathrm{p}<0,05)$.

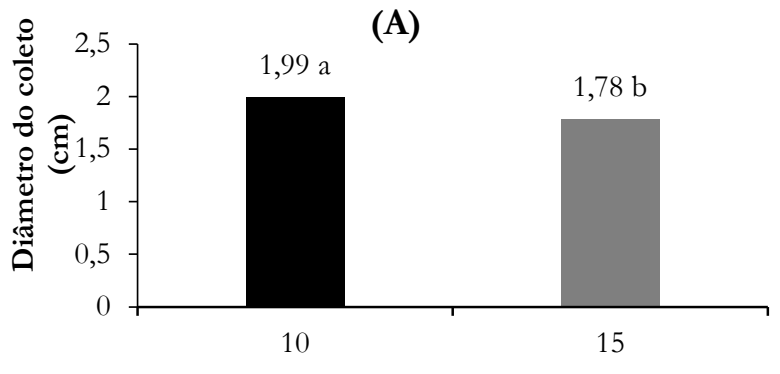

Lâminas de irrigação (mm)

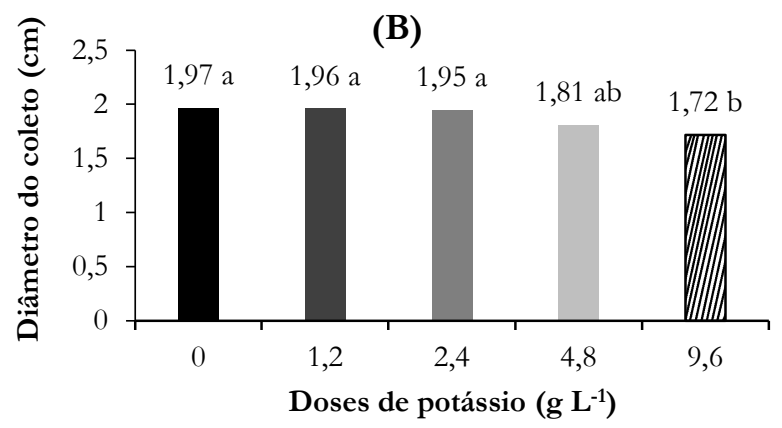

Figura 2. A) Diâmetro do coleto em função das lâminas de irrigação e B) Diâmetro do coleto em função das doses de potássio. Médias comparadas entre si pelo teste de Tukey a 5,0\% de probabilidade $(\mathrm{p}<0,05)$.

Figure 2. Root collar diameter as a function of the irrigation levels; and B) Root collar diameter as a function of $\mathrm{K}_{2} \mathrm{O}$ levels. Means compared to each other by Tukey test at $5.0 \%$ probability $(\mathrm{p}<0,05)$.

\subsection{Massa seca da parte aérea}

A análise de variância da massa seca da parte aérea não apresentou interação significativa entre os fatores principais (doses e lâminas de irrigação) pelo teste $\mathrm{F}$ à $5 \%$ de probabilidade de erro. Os respectivos resultados são apresentados na Figura 3, após a aplicação do teste de Tukey à $5 \%$ de probabilidade.

\subsection{Massa seca da raiz}

Os resultados da ANOVA para a massa seca da raiz demonstraram a existência de interação significativa entre os fatores principais (doses e lâminas de irrigação) pelo teste de $\mathrm{F}$ à $5 \%$ de probabilidade de erro, o que acarretou na necessidade de proceder com os desdobramentos de tais fatores e, consequentemente, a comparação de médias pelo teste de Tukey a $5 \%$ de probabilidade (Tabela 4).

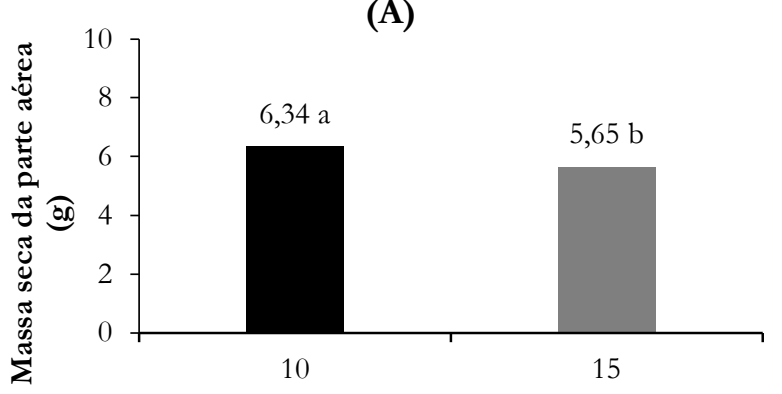

Lâminas de irrigação (mm)

(B)

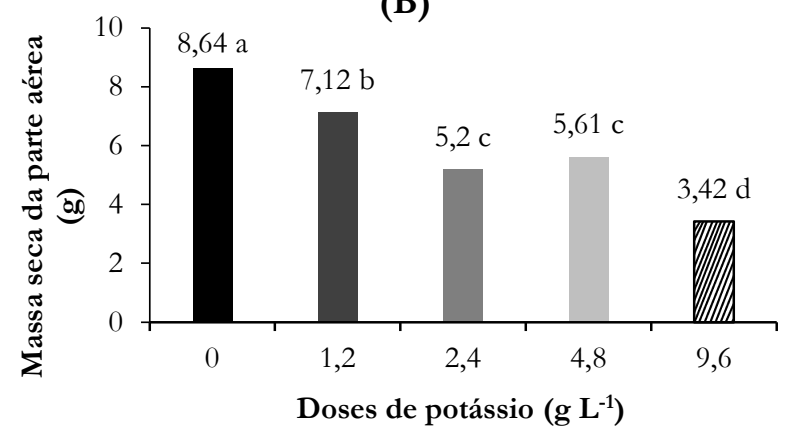

Figura 3. A) Massa seca da parte aérea em função das lâminas de irrigação; e B) Massa seca da parte aérea em função das doses de $\mathrm{K}_{2} \mathrm{O}$. Médias comparadas entre si pelo teste de Tukey a 5,0\% de probabilidade $(\mathrm{p}<0,05)$.

Figure 3. A) Dry mass of the aerial part as a function of the irrigation levels; and B) Dry mass of the aerial part as a function of the $\mathrm{K}_{2} \mathrm{O}$ levels. Means compared to each other by Tukey test at $5.0 \%$ probability $(\mathrm{p}<0,05)$.

A partir dos resultados apresentados na Tabela 4 foi possível delimitar que as melhores doses dentro de cada irrigação foram: a) em L1, a testemunha $(3,86 \mathrm{~g})$ e a $2,4 \mathrm{~g} \mathrm{~L}^{-1}$ $(3,23 \mathrm{~g})$; b) em L2, a testemunha (2,96 g) e 1,2 $\mathrm{g} \mathrm{L}^{-1}(2,56 \mathrm{~g})$ e $2,4 \mathrm{~g} \mathrm{~L}^{-1}(2,28 \mathrm{~g})$; c) as demais não apresentaram diferenças estatísticas. As lâminas que apresentaram melhores 
resultados, sob influência de cada dose foram: $15 \mathrm{~mm}$ nas doses $0 \mathrm{~g} \mathrm{~L}^{-1}(3,86 \mathrm{~g}), 1,2 \mathrm{~g} \mathrm{~L}^{-1}(3,0 \mathrm{~g})$ e $2,4 \mathrm{~g} \mathrm{~L}^{-1}(3,23 \mathrm{~g}), 4,8$ $\mathrm{g} \mathrm{L}^{-1}(2,92 \mathrm{~g})$ e sem diferença estatística na dose 9,6 $\mathrm{g} \mathrm{L} \mathrm{L}^{-1}$.

Tabela 4. Massa seca da raiz (g) em função das lâminas de irrigação e das doses de $\mathrm{K}_{2} \mathrm{O}$.

Table 4. Dry mass of the root $(\mathrm{g})$ as a function of the irrigation depths and $\mathrm{K}_{2} \mathrm{O}$ doses.

\begin{tabular}{cccccc}
\hline \multirow{2}{*}{ Lâminas de Irrigação } & \multicolumn{5}{c}{ Doses de $\mathrm{K}_{2} \mathrm{O}$} \\
\cline { 2 - 6 } & $0 \mathrm{~g} \mathrm{~L}^{-1}$ & $1,2 \mathrm{~g} \mathrm{~L}^{-1}$ & $2,4 \mathrm{~g} \mathrm{~L}^{-1}$ & $4,8 \mathrm{~g} \mathrm{~L}^{-1}$ & $9,6 \mathrm{~g} \mathrm{~L}^{-1}$ \\
\hline $\mathrm{L} 1$ & $3,86 \mathrm{~g} \mathrm{aA}$ & $3,0 \mathrm{~g} \mathrm{bA}$ & $3,23 \mathrm{~g} \mathrm{abA}$ & $2,92 \mathrm{~g} \mathrm{bA}$ & $1,85 \mathrm{~g} \mathrm{cA}$ \\
$\mathrm{L} 2$ & $2,96 \mathrm{~g} \mathrm{aB}$ & $2,56 \mathrm{~g} \mathrm{aB}$ & $2,28 \mathrm{~g} \mathrm{abB}$ & $1,76 \mathrm{~g} \mathrm{bB}$ & $1,67 \mathrm{~g} \mathrm{bA}$ \\
\hline
\end{tabular}

em que: Médias seguidas pela mesma letra maiúscula nas colunas e minúscula nas linhas não diferem pelo teste de Tukey a $5 \%$ de probabilidade ( $<<0,05)$.

Foi possível perceber com os cálculos de discrepância percentual que os melhores resultados encontrados na Altura da Parte Aérea (HPA) são cerca de 43\% superiores aos piores resultados; no Diâmetro do Coleto (DC) essa diferença se mantém por volta de 13\%; na Matéria Seca da Parte Aérea (MSPA) a discrepância é de 60\%; e na Matéria Seca Radicular (MSR) é de 52\%.

\section{DISCUSSÃO}

A deficiência e o excesso de elementos minerais nas mudas apresentam sintomas semelhantes, podendo prejudicar as funções específicas do metabolismo vegetal interferindo no crescimento das mesmas (LEAL; PRADO, 2008). Sendo assim, os piores resultados de crescimento em altura das mudas e de diâmetro do coleto com as maiores doses, podem ser justificados pelo excesso de potássio, que acabou por gerar níveis de toxidez nas mudas. De acordo com Farias et al. (2009), quando o composto possui alto índice salino, o potencial osmótico do substrato é baixo, fazendo com que a água fique retida na solução salina, e assim os sais se tornam cada vez mais disponíveis para a planta. Souza et al. (2010) afirmaram que o alto teor de sais presentes nos compostos tem o poder de inibir a germinação em virtude da diminuição do potencial osmótico, resultando assim em prejuízos nas fases seguintes do processo de produção.

Em relação às lâminas de irrigação, os resultados da interação mostram que à medida que se aumentavam as doses de potássio, a altura das mudas diminuía, o que pode ser explicado por Bosco et al. (2009) quando relataram que nas maiores doses de potássio ocorre o aumento do potencial osmótico do substrato e dificulta a absorção de água pelas raízes, o que prejudicará o desenvolvimento da planta. No caso do diâmetro, que não apresentou interação entre as doses de potássio e de irrigação, percebe-se que a maior lâmina apresentou melhores resultados, possivelmente por que a lâmina de $10 \mathrm{~mm}$ foi caracterizada como insuficiente, condição que pode afetar diretamente o crescimento em altura e em diâmetro, reduzindo a expansão das células e formação de parede, e, consequentemente, interferindo na produção de reguladores de crescimento (TAIZ; ZEIGER, 2009).

Bernardino et al. (2019), perceberam que a irrigação sozinha não influenciou o crescimento de mudas de eucalipto. Segundo os autores, as características do substrato foram muito importantes para os resultados encontrados. Os autores também encontraram, em suas pesquisas literárias, trabalhos que apresentaram resultados diretamente proporcionais entre as lâminas de irrigação e o aumento na altura das plântulas.

A massa seca da parte aérea seguiu a mesma tendência da altura e do diâmetro da Parte Aérea, de decréscimo com as maiores dosagens de $\mathrm{K}_{2} \mathrm{O}$. Sendo assim o tratamento testemunha (sem adição de potássio) foi o que apresentou melhores resultados, seguido do T2 $\left(1,2 \mathrm{~g} \mathrm{dm}^{-3}\right.$ de $\left.\mathrm{K}_{2} \mathrm{O}\right)$, em terceiro lugar está o T3 $\left(2,4 \mathrm{~g} \mathrm{dm}^{-3} \mathrm{de}_{2} \mathrm{O}\right)$, e T4 $\left(4,8 \mathrm{~g} \mathrm{dm}^{-3}\right.$ de $\left.\mathrm{K}_{2} \mathrm{O}\right)$ e com os piores números ficou o T5 $\left(9,6 \mathrm{~g} \mathrm{dm}^{-3} \mathrm{de}\right.$ $\mathrm{K}_{2} \mathrm{O}$ ). Os valores referentes à Matéria Seca Radicular (MSR) do presente trabalho seguiram o mesmo padrão dos parâmetros anteriormente citados. Nesse caso os tratamentos que apresentaram melhores resultados foram a testemunha $\mathrm{e}$ o T2, e o pior foi o com 9,6 $\mathrm{g} \mathrm{L}^{-1}$. Assim como nos resultados referentes à altura e ao diâmetro, os valores decrescentes encontrados na MSPA e MSR podem estar relacionados aos efeitos do potencial salino do $\mathrm{KCl}$ quando em contato com as mudas e/ou sementes.

Segundo Mendonça et al. (2010), as mudas de espécies florestais apresentam uma estratégia de sobrevivência quando submetidas a níveis de sal desfavoráveis, que influenciam na redução da massa seca e da área foliar.

\section{CONCLUSÕES}

As maiores doses de potássio não garantiram às mudas melhores condições morfológicas e tão pouco apoiaram a redução da lâmina de irrigação, sendo assim, a redução da lâmina de irrigação, de $15 \mathrm{~mm}$ para $10 \mathrm{~mm}$, não favoreceu a produtividade das mudas. A adubação potássica só é recomendada a níveis que não ultrapassem os valores de salinidade ideais, contudo, a dose de $1,2 \mathrm{~g} \mathrm{~L}^{-1}$ de $\mathrm{K}$ é a mais indicada. A principal variável das mudas afetada foi a biomassa, visto que a massa seca da parte aérea e a massa seca das raízes apresentaram maiores discrepâncias percentuais entre os melhores e os piores resultados. Devido os dados estatísticos iguais, a lâmina de irrigação pode ser diminuída em $5 \mathrm{~mm}$.

\section{AGRADECIMENTOS}

Os autores ao Instituto Federal de Educação, Ciência e Tecnologia do Norte de Minas Gerais - Campus Salinas por dar todo o suporte necessário para a realização da pesquisa, à Coordenação de Aperfeiçoamento de Pessoal de Nível Superior (CAPES) Código de financiamento 001, à Fundação de Amparo à Pesquisa e Inovação do Espírito Santo (FAPES) e ao Conselho Nacional de Desenvolvimento Científico e Tecnológico (CNPq).

\section{REFERÊNCIAS}

ALFENAS, A. C.; ZAUZA, E. A. V.; MAFIA, R. G.; ASSIS, T. F. Clonagem e doenças do eucalipto. 2 ed. Viçosa: UFV, 2009. 500 p.

ALVARES, C. A.; STAPE, J. L.; SENTELHAS, P. C.; GONÇALVES, J. L. de M.; SPAROVEK, G. Köppen's climate classification map for Brazil. Meteorologische 
Zeitschrift, Stuttgart, v. 22, n. 6, p. 711-728, 2014. https://dx.doi.org/10.1127/0941-2948/2013/0507

BATTIE-LACLAU, P.; DELGADO-ROJAS, J. S.; CHRISTINA, M.; NOUVELLON, Y.; BOUILLET, J. P.; PICCOLO, M. de C.; MOREIRA, M. Z.; GONÇALVES, J. L. de M.; ROUPSARD, O.; LACLAU, J. P. Potassium fertilization increases water-use efficiency for stem biomass production without affecting intrinsic water-use efficiency in Eucalyptus grandis plantations. Forest Ecology and Management, v. 364, p. 77-89, 2016. https://doi.org/10.1016/j.foreco.2016.01.004

BERNARDINO, L. T.; BONOMO, R.; SOUZA, J. M. Desenvolvimento inicial de mudas de eucalipto sob diferentes lâminas de irrigação. Revista Brasileira de Agricultura Irrigada, Fortaleza, v. 13, n. 1, p. 31693179 , 2019.

DOI: https://doi.org/10.7127/RBAI.V13N100833

BOSCO, M. R. O.; OLIVEIRA, A. B.; HERNANDEZ, F. F.; LACERDA, C. F. Efeito do $\mathrm{NaCl}$ sobre o crescimento, fotossíntese e relações hídricas de plantas de berinjela. Ceres, Viçosa, v. 56, n. 3, p. 296-302, 2009.

BUSATO, J. G.; ZANDONADI, D. B.; SOUZA, I. M.; MARINHO, E. B.; DOBBSS, L. B.; MÓL, A. R. Efeito do extrato húmico solúvel em água e biofertilizante sobre o desenvolvimento de mudas de Callophyllum brasiliense. Pesquisa Florestal Brasileira, Colombo, v. 36, n. 86, p. 161-168,

2016. https://doi.org/10.4336/2016.pfb.36.86.1024

D'AVILA, F. S.; PAIVA, H. N.; LEITE, H. G.; BARROS, N. F.; LEITE, F. P. Efeito do potássio na fase de rustificação de mudas clonais de Eucalipto. Árvore, Viçosa, v. 35, n. 1, p. 13-19, 2011. https://doi.org/10.1590/S0100-67622011000100002

FARIAS, S. G. G.; FREIRE, A. L. de O.; SANTOS, D. R.; BAKKE, I. A.; SILVA, R. B. Efeitos dos estresses hídrico e salino na germinação de sementes de gliricidia [Gliricidia sepium (JACQ.) STEUD.]. Caatinga, Mossoró, v. 22, n. 4, p. 152-157, 2009.

FERNANDES, M. S.; SOUZA, S. R.; SANTOS, L. A. Nutrição Mineral de Plantas. 2. ed. Viçosa - MG, 2018.

FERNÁNDEZ, M.; ALEJOS, J.; ANDIVIA, E.; VÁZQUEZ-PIQUÉ, J.; RUIZ, F.; LÁPEZ, F.; TAPIAS, R. Eucalyptus urograndis biomass production for energy purposes exposed to a Mediterranean climate under different irrigation and fertilisation regimes. Biomass and Bioenergy, v. 111, p. 22-30, 2018. https://doi.org/10.1016/j.biombioe.2018.01.020

FERREIRA, D. F. Sisvar: a Guide for its Bootstrap procedures in multiple comparisons. Ciênc. agrotec. [online]. 2014, vol.38, n.2 [citado 2015-10-17], pp. 109112. Disponible en: ISSN 1413-7054. http://dx.doi.org/10.1590/S1413-70542014000200001

GIRARDI, E. A.; BRANDÃO, A. D.; COELHO, R. D.; COUTO, H. T. Z.; BUCKERIDGE, M. S.; MOURÃO FILHO, F. de A. A. Regulated deficit irrigation benefits the production of container-grown citrus nursery trees. Trees, v. 32, p. 1751-1766, 2018. https://doi.org/10.1007/s00468-018-1748-2

GONÇALVES, K. S.; SOUSA, A. de P.; VELINI, E. D. Aplicação de reguladores vegetais e de fosfito de potássio em mudas de eucalipto submetidas à deficiência hídrica. Irriga, Botucatu, v. 20, n. 2, p. 273-285, 2015. https://doi.org/10.15809/irriga.2015v20n2p273
HERNANDEZ-SANTANA, V.; FERNÁNDEZ, J. E.; CUEVAS, M. V.; PEREZ-MARTIN, A.; DIAZESPEREJO, A. Photosynthetic limitations by water deficit: Effect on fruit and olive oil yield, leaf area and trunk diameter and its potential use to control vegetative growth of super-high-density olive orchards. Agricultural Water Management, v. 184, p. 9-18, 2017. http://dx.doi.org/10.1016/j.agwat.2016.12.016

LEAL, R. M.; PRADO, R. M. Desordens nutricionais no feijoeiro por deficiência de macronutrientes, boro e zinco. Revista Brasileira de Ciências Agrárias, Recife, v. 3, n. 4, p. 301-306, 2008. https://doi.org/10.5039/agraria.v3i4a332

LIMA, G. S.; BROETTO, F.; SOUSA, A. de P.; CORREIA, J. de S.; SILVA, A. O. Impactos nutricionais e produção de pimentão submetido à deficiência hídrica. Irriga, Botucatu, v. 21, n. 4, p. 724-735, 2016. https://doi.org/10.15809/irriga.2016v21n4p724-735

MARGUERIT, E. The genetics of water-use efficiency and its relation to growth in maritime pine. Journal of Experimental Botany, v. 65, n. 17, p. 4757-4768, 2014. https://doi.org/10.1093/jxb/eru226

MARQUES, D. J.; BIANCHINI, H. C.; LOBATO, A. K. da S.; SILVA, W. F. Potassium fertilization in the production of vegetables and fruits. In: Potassium-Improvement of Quality in Fruits and Vegetables Through Hydroponic Nutrient Management. IntechOpen, 118 p. 2018. https://doi.org/10.5772/intechopen.72854

MARTINS, G. S.; FREITAS, N. C.; MÁXIMO, W. P. F.; PAIVA, L. V. Gene expression in two contrasting hybrid clones of Eucalyptus camaldulensis x Eucalyptus urophylla grown under water deficit conditions. Journal of Plant Physiology, v. 229, p. 122-131, 2018. https://doi.org/10.1016/j.jplph.2018.07.007

MENDONÇA, A. V. R.; CARNEIRO, J. G. de A.; FREITAS, T. A. S.; BARROSO, D. G. Physiological characteristics of Eucalyptus spp seedlings submitted to saline stress. Ciência Florestal, Santa Maria, v. 20, n. 2, p. 255-267, 2010. http://doi.org/10.5902/19805098

PEGO, M. F. F.; ASSIS, A. L.; CABACINHA, C. D. Classificação de sítios florestais em povoamentos de eucalipto na microrregião de Salinas, Minas Gerais. Enciclopédia Biosfera, Goiânia, v. 11 n. 21, p. 534-542, 2015.

QUEIROZ, T. B.; ROCHA, S. M. G.; FONSECA, F. S. A.; MARTINS, E. R.; ALVARENGA, I. C. A. Efeitos do déficit hídrico no cultivo de mudas de eucalipto. Irriga, Botucatu, v. 22, n. 4, p. 659-674, 2017. https://doi.org/10.15809/irriga.2017v22n4p659-674

RESENDE, R. T. Environmental uniformity, site quality and tree competition interact to determine stand productivity of clonal Eucalyptus. Forest Ecology and Management, v. $410, \quad$ n. $15 \quad$ p.76-83, 2018. https://doi.org/10.1016/j.foreco.2017.12.038

RODRIGUES, S. B. S.; MANTOVANI, E. C.; OLIVEIRA, R. A.; PAIVA, H. N.; ALVEZ, M. E. B. Necessidades hídricas de mudas de eucalipto na região Centro-Oeste de Minas Gerais. Irriga, Botucatu v. 16, p. 212- 223, 2011. https://doi.org/10.15809/irriga.2011v16n2p212

SILVA, R. B. G.; SILVA, M. R. Effects of water management on growth, irrigation efficiency and initial development of Aspidosperma polyneuron seedlings. African Journal of Agricultural Research, Abraka, v. 10, p. 3562-3569, 2015. https://doi.org/10.5897/AJAR2015.10088 
SOUZA, L. R.; PERES, F. S. B. Uso de biofertilizantes à base de aminoácidos na produção de mudas de Eucalyptus dunii. Pesquisa Florestal Brasileira, Colombo, v. 36, n. 87, p. 211-218, 2016. http://doi.org/10.4336/2016.pfb.36.87.1127

SOUZA, Y. A. Efeito da salinidade na germinação de sementes e no crescimento inicial de mudas de pinhãomanso. Revista Brasileira de Sementes, Londrina, v. 32, n. 2, p. 83-92, 2010. https://doi.org/10.1590/S010131222010000200010

TAIZ, L.; ZEIGER, E. Fisiologia vegetal. 4. ed. Porto Alegre: Artmed, 2009. 819 p.

TAVARES, L. C.; TUNES, L. M.; BRUNES, A. P.; FONSECA, D. A. R.; RUFINO, C. de A.; BARROS, A. C. S. A. Potássio via recobrimento de sementes de soja: efeitos na qualidade fisiológica e no rendimento. Ciência Rural, Santa Maria, v. 43, n. 7, p. 1196-1202, 2013. http://dx.doi.org/10.1590/S0103-84782013000700009

ZENG, X.; CHEN, C.; LIU, A.; WEI, H.; ZHANG, H.; HUANG, G.; WU, Y. Planning a sustainable regional irrigated production and forest protection under land and water stresses with multiple uncertainties. Journal of Cleaner Production, v. 188, p. 751-762, 2018. https://doi.org/10.1016/j.jclepro.2018.04.028 